\title{
FACHADAS ATIVAS: Uma alternativa para a melhora da relação entre arquitetura e cidade
}

\author{
Vanessa Guerini Scopel \\ Universidade Ritter Dos Reis / Universidade Presbiteriana Mackenzie \\ va_scopel@yahoo.com.br
}

\section{RESUMO}

O trabalho em questão é uma reflexão acerca da política das "fachadas ativas", atualmente já presente em algumas reformulações de planos diretores e exposta nos debates sobre a gestão do uso do solo urbano. $O$ objetivo do artigo é contribuir para a discussão relacionada ao tema das fachadas ativas, demonstrando a importância de promover estas políticas incentivadoras e de pensar a arquitetura para além dos limites do lote. Tendo como base uma pesquisa documental, iconográfica e legislativa, pretende-se explicar a diretriz da fachada ativa presente nos planos diretores de três cidades brasileiras - São Paulo, Belo Horizonte e Curitiba - e discutir sobre a sua possível contribuição para o melhoramento do ambiente urbano. Por fim, ressaltar a importância de se pensar o planejamento da cidade para as pessoas, promovendo, mesmo que pontualmente e aos poucos, através desta estratégia, um tecido urbano mais articulado e coeso.

Palavras-chave: fachada ativa; arquitetura; cidade.

\section{ABSTRACT}

The work in question is a reflection on the politics of the "active faces", already present in some reformulations of master plans and exposed in the debates on the management of urban land use. The objective of this article is to contribute to the discussion related to the theme of the active faces, demonstrating the importance of promoting these incentive political and thinking about the architecture beyond the limits of the lot. Based on a documentary, iconographic and legislative research, it is intended to explain the guideline of the active face present in the master plans of three Brazilian cities - São Paulo, Belo Horizonte and Curitiba - and to discuss their possible contribution to the improvement of the urban environment . Finally, to emphasize the importance of thinking about city planning for people, promoting, even if punctually and gradually, through this strategy, a more articulated and cohesive urban fabric.

Keywords: active face; architecture; city. 


\section{INTRODUÇÃO}

A rotina agitada, principalmente dos centros urbanos maiores, a falta de segurança que assola pequenas e grandes cidades e a infraestrutura pública muitas vezes precária e faltante, contribuem para evidenciar a realidade das cidades brasileiras. Em virtude de o meio externo e público estar, em alguns casos, mau cuidado e inseguro, se multiplicam espaços internos de convivência, como cinemas, complexos de lazer e condomínios fechados, que acabam por segregar cada vez mais as cidades, pois os acessos a esse locais são limitados a pessoas de classe média-alta.

A crescente violência é um dos fatores pelos quais as pessoas estão preferindo se enclausurar em suas residências e evitar o contato com a rua. A tendência de prédios murados, casas cercadas e quadras fechadas acaba por contribuir ainda mais para esta preocupante realidade. O que acontece é que quanto mais a edificação se voltar para dentro e menos para o exterior, mais inseguro será seu entorno público.

Edificações onde o limite com a rua (a fachada) não é permeável ou não permite qualquer conexão do interior com o exterior, acaba por tornar a calçada muito mais insegura. Diante destas arquiteturas segregacionistas, a rua passa a ter apenas a função de circulação de carros e as calçadas são vistas como espaços para mendigos e moradores de rua, quando na verdade, estes locais de caráter público, deveriam ser usados por todos, promovendo o encontro e a convivência e a partir deste uso, tornar a cidade mais segura e viva.

A ideia principal da pesquisa em questão baseia-se no sentido de perceber como a arquitetura privada pode ser determinante na melhora dos espaços públicos, considerando a escala da calçada e da rua, ou seja, como o próprio edifício pode qualificar o entorno em que está inserido. Este trabalho trata a arquitetura e o meio urbano como partes indissociáveis de um mesmo todo, desta maneira o objeto de estudo é justamente o elemento da edificação que tem o contato com a calçada, que promove a articulação entre a arquitetura e o contexto onde está inserida, neste caso, as fachadas ativas ou "plinths" (KARSSENBERG et al, 2015).

Tanto as grandes metrópoles quanto as cidades mais compactas necessitam de térreos que possam articular as edificações ao meio urbano, possibilitando à população a vivência da urbanidade e a participação do funcionamento da cidade. Uma linha ou espaço intermediário é que divide os limites do edifício e da cidade, definindo a porção que cabe a cada um. Esta zona fica situada no pavimento térreo, aos olhos do observador, e é ali que pode acontecer o elo e a articulação entre a arquitetura e o contexto onde está inserida, melhorando a relação entre arquitetura e cidade.

Este trabalho tem a intenção de contribuir para as pesquisas relacionadas ao desenho urbano, às diretrizes de uso e ocupação do solo, e consequentemente à forma de implantação da edificação no lote, possibilitando, através dos pavimentos térreos das construções, e da diretriz das "fachadas ativas" a melhora do meio urbano e do entorno da edificação.

\section{O CONCEITO DE FACHADA ATIVA}

Pode-se definir por fachadas ativas - termo usado nos Planos Diretores brasileiros - ou plinths, termo usado no livro A cidade ao nível dos olhos (2015), por andares térreos das edificações conformados nos alinhamentos frontais do lote (figura 1), com portas, janelas ou vitrines voltadas para a rua. 


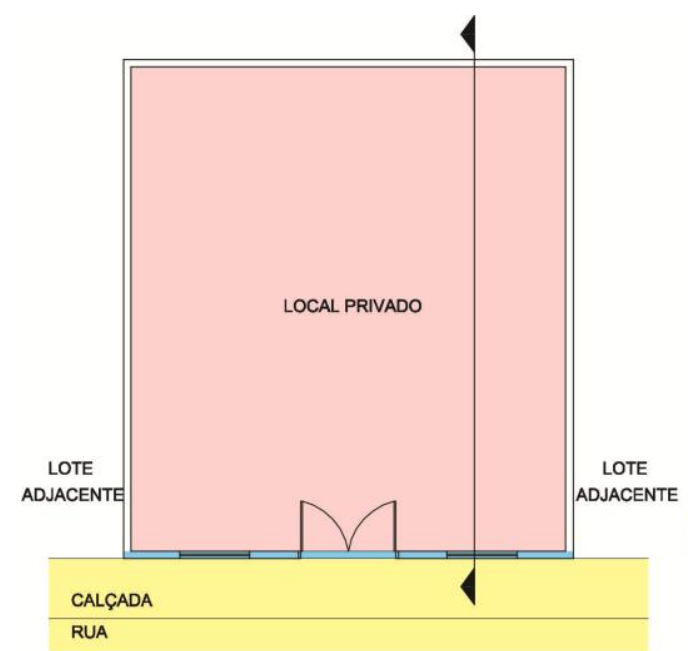

Planta Baixa

Sem escala
LEGENDA

Privado

Conexão

Público

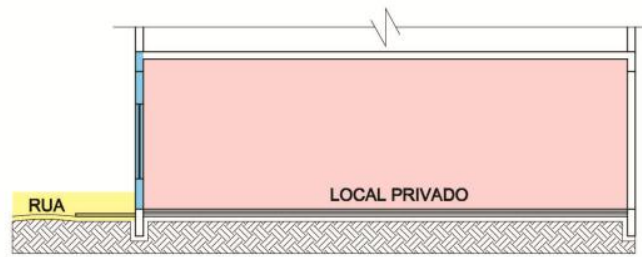

Corte

Sem escala

Figura 1 - Esquema demonstrando exemplo de edificação que apresenta uma fachada ativa FONTE: Do autor, 2016

Esses andares no nível da rua podem ser usados para comércio, serviços ou equipamentos, possibilitando a permeabilidade física e/ou visual e atividades e usos constantes nestes espaços. Todas as fachadas cegas, com grandes muros, sem qualquer tipo de permeabilidade ou transparências são o elemento contrário aos plinths. O objetivo das fachadas ativa é priorizar a interação do edifício com o pedestre, estimulando-o visualmente e socialmente. Essa interface direta entre o público e privado que se dá através das fachadas ativas, além de facilitar o convívio e a relação entre a população e usuários do local, permite o controle sobre o que acontece na calçada, tornando este espaço mais seguro.
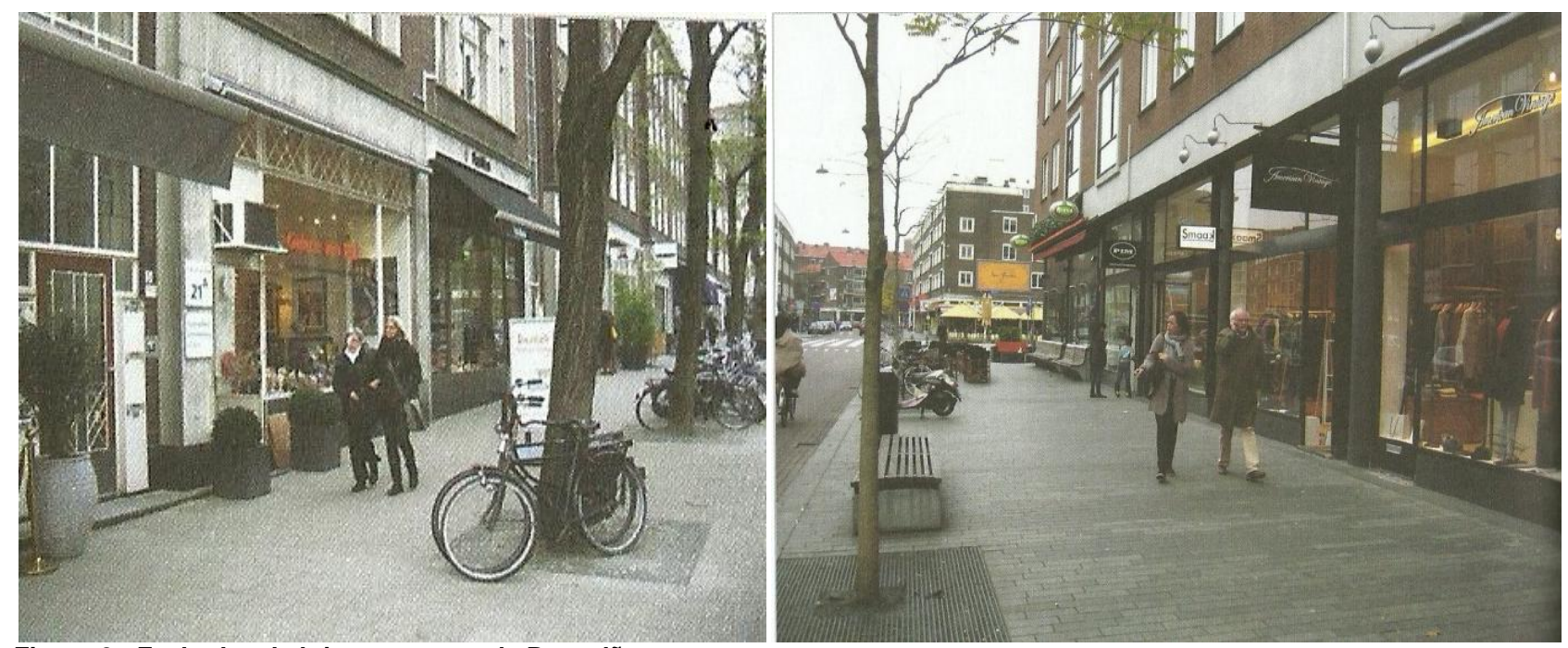

Figura 2 - Fachadas de lojas no centro de Roterdã

Fonte: KARSSENBERG et al., 2015

Essa tipologia torna a passagem dos pedestres mais interessante, pois permite que eles possam ver e ser vistos, portanto contribui para a relação entre os domínios. 

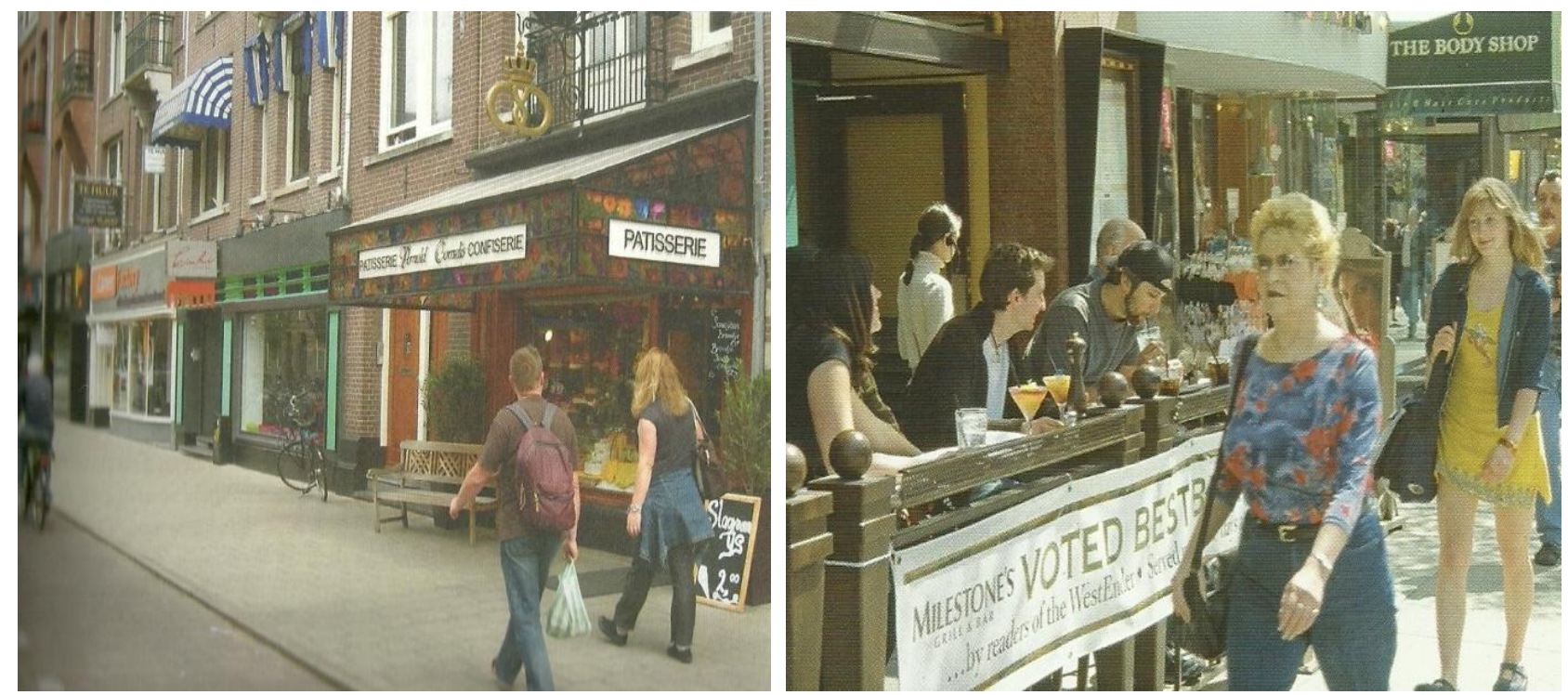

Figura 3 - Fachadas de lojas em Amsterdã e bares em Vancouver Fonte: KARSSENBERG et al., 2015

Voltada aos espaços comerciais e de serviços, essa conformação permite ainda que essas edificações utilizem o espaço público em frente às fachadas, tornando-as ainda mais atrativas.
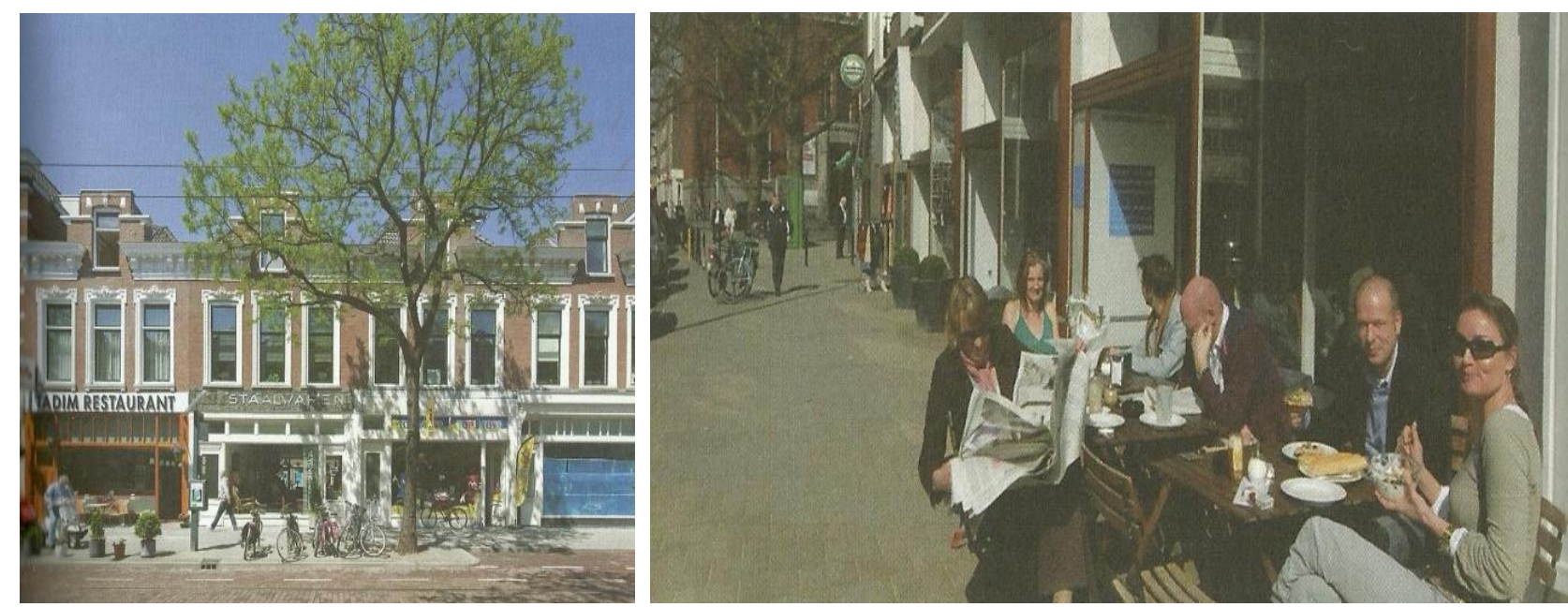

Figura 4 - Fachadas em Botersloot na cidade de Roterdã

Fonte: KARSSENBERG et al., 2015

\section{A FACHADA ATIVA COMO ELEMENTO DE TRANSIÇÃO}

Considerando a importância dos espaços públicos ao ar livre para as cidades, e principalmente as possibilidades de conexões entre a edificação e estes espaços, visto que, conforme expõe Philipe Panerai (2006), eles não funcionam individualmente, destaca-se o papel da arquitetura como promotora desta integração entre os dois conjuntos.

Em se tratando de uma pesquisa que estuda a escala da rua, calçada e lote, o modo de implantar o edifício no terreno e a conformação do pavimento térreo do mesmo, são os pontos principais para que seja possível a conexão entre os dois lados. Conforme lista Castex e Panerai (1970), no artigo Notas sobre a Estrutura do Espaço Urbano, essa ligação pode ser direta, indireta ou nula. Podendo ser considerada direta através das fachadas alinhadas ao limite do lote, ou seja, uma fachada ativa. 
É valido destacar que, o pavimento térreo é o local que pode estabelecer a ligação entre a edificação e o espaço público, pois é ele que está "ao nível dos olhos" (KARSSENBERG et al., 2015) do observador. Porém, a conexão depende de diversos elementos arquitetônicos relacionados às formas de ligação dos domínios, que, se presentes no pavimento térreo, podem torná-lo ativo e consequentemente ligado ao espaço urbano.

As fachadas ativas ou plinths são percebidas, neste artigo, como elementos de transição, ou seja, elos entre a arquitetura e a cidade. Denominam-se elementos, pois fazem parte de um todo, que é o edifício, e de transição, pois são responsáveis pela passagem e/ou ligação entre os espaços de caráter público e privado. Estes elementos de transição são mencionados em livros de importantes autores, que os tratam através de variadas nomenclaturas.

O autor Jan Gehl (2013), trata dos locais onde a arquitetura encontra a rua como "espaços de transição suave." O espaço de transição ao longo dos andares térreos, para ele, é uma zona onde se localizam as portas de entrada e os pontos de troca entre interior e exterior. Sendo assim, Gehl (2013) defende que as transições proporcionam uma oportunidade para a vida, tanto dentro das edificações quanto logo em frente a elas, de interagir com o restante da cidade.

O autor Herman Hertzberger (1999), em seu livro Lições de Arquitetura, trata da transição do público para o privado como um "intervalo", podendo ser desde as soleiras e degraus, até as vitrines e janelas. O autor ressalta que o "intervalo" é um importante mecanismo para eliminar a rígida divisão entre as áreas de diferentes características. Portanto, a questão está em criar elementos intermediários que, mesmo pertencendo tanto ao domínio público quanto ao privado, "sejam igualmente acessíveis para ambos os lados." (HERTZBERGER, 1999), podendo constituir a condição espacial para o diálogo e o encontro entre as áreas de ordens diferentes.

Kevin Lynch (1980), em seu livro A imagem da cidade, apresenta alguns elementos que, quando trabalhados no projeto, podem conseguir determinar uma forma satisfatória para a cidade. Ele trata dos elementos de transição como limites, destacando que são uma relevante característica organizadora, principalmente no que diz respeito a manter unidas áreas divergentes.

Os limites são os elementos lineares não usados nem considerados pelos habitantes como vias. São as fronteiras entre duas partes, interrupções lineares na continuidade, costas marítimas ou fluviais, cortes do caminho-de-ferro, paredes, locais de desenvolvimento. (LYNCH, 1980)

Os autores ainda destacam que esses elementos têm a potencialidade de serem articuladores do tecido urbano, promovendo uma malha mais coesa. Quando bem elaborados e considerados tanto no âmbito do projeto de arquitetura, quanto na discussão e implementação de leis e regulamentações pelo poder público, podem contribuir para a segurança e a socialização, criando espaços de integração e promovendo a convivência. Porém atualmente esses elementos, conforme a crítica de Camillo Sitte (1992), estão fadados ao desaparecimento, pois "são vítimas da especulação imobiliária, que não para de abrir ruas e construir pardieiros escuros e fétidos, sem a menor possibilidade de avistar um pedacinho do céu." (SITTE, 1992)

Herman Hertzberger (1999) destaca que muito dos comportamentos dos moradores e cidadãos depende dos desenhos da rua, da calçada e das fachadas. Além disso, esses elementos apresentam muitos outros benefícios para os meios urbanos e para os cidadãos. Balsini (2014) expõe que o "espaço de transição" funciona como um local adequador ou dosador e opera como "ajuste na predisposição do usuário com o contato com o ambiente de característica distinta." (BALSINI, 2014)

\section{OS PLANOS DIRETORES E A DIRETRIZ DE FACHADAS ATIVAS}

Para este item foram escolhidas três cidades brasileiras que já apresentam uma discussão inicial sobre a diretriz da fachada ativa, que são elas, São Paulo, Belo Horizonte e Curitiba. Essas cidades tem a revisão de seus Planos Diretores mais evoluída em relação a esta estratégia, diferente de outros municípios que ainda não iniciaram esta discussão. Essas importantes cidades brasileiras já iniciaram o processo de incentivar as relações do espaço privado com o espaço público, adotando a diretriz da fachada ativa, e demonstrando, mesmo que inicialmente, a preocupação de conceber estratégias que possam promover uma melhor relação entre a arquitetura e a cidade. 


\subsection{São Paulo}

São Paulo é a cidade brasileira que tem seu plano de estratégias mais desenvolvido em relação aos outros municípios do país. Em 2013 formulou um Projeto de Lei de Revisão de seu Plano Diretor com uma série de instrumentos e objetivos que têm o intuito de melhorar a lógica de funcionamento dessa megalópole brasileira. O Plano Diretor Estratégico de São Paulo foi aprovado, em 2014, pela Lei 16.050/2014. Nesta revisão a gestão municipal passou a se preocupar com novos temas. Dentre as principais estratégias encontram-se as fachadas ativas.

A revisão do Plano se preocupa com a coletividade, através da seção II, Artigo 36, onde diz que "as ações públicas e privadas com interferência na paisagem urbana deverão atender ao interesse público". A Lei 16.050/2014 procura aprimorar os processos de planejamento e gestão urbana e ambiental no Município de São Paulo. Para isso, propõe alguns instrumentos e ações principais, combinando estratégias de: preservação, conservação e recuperação urbana e ambiental; qualificação das áreas urbanas consolidadas localizadas nas porções centrais da cidade; estruturação metropolitana; desenvolvimento de eixos de estruturação da transformação urbana que pretendem otimizar o aproveitamento do solo urbano ao longo da rede de transporte coletivo e de redução da vulnerabilidade social e urbana. A estratégia de desenvolvimento de eixos de estruturação e transformação urbana tem por objetivo

Orientar a produção imobiliária para áreas localizadas ao longo dos eixos de transporte coletivo público com novas formas de implantação de empreendimentos que promovam melhores relações entre os espaços públicos e privados e contribuam para a redução dos tempos e distâncias de deslocamentos. (SÃO PAULO, Lei 16.050 de 2014)

Esta estratégia, segundo a gestão municipal, é uma maneira clara de otimização da infraestrutura existente que visa potencializar o aproveitamento do solo urbano. "Estes eixos foram definidos por estarem numa faixa de 150 metros de cada lado dos corredores de ônibus e em um raio de $400 \mathrm{~m}$ das estações de metrô e trem." (SÃO PAULO, Lei 16.050 de 2014)

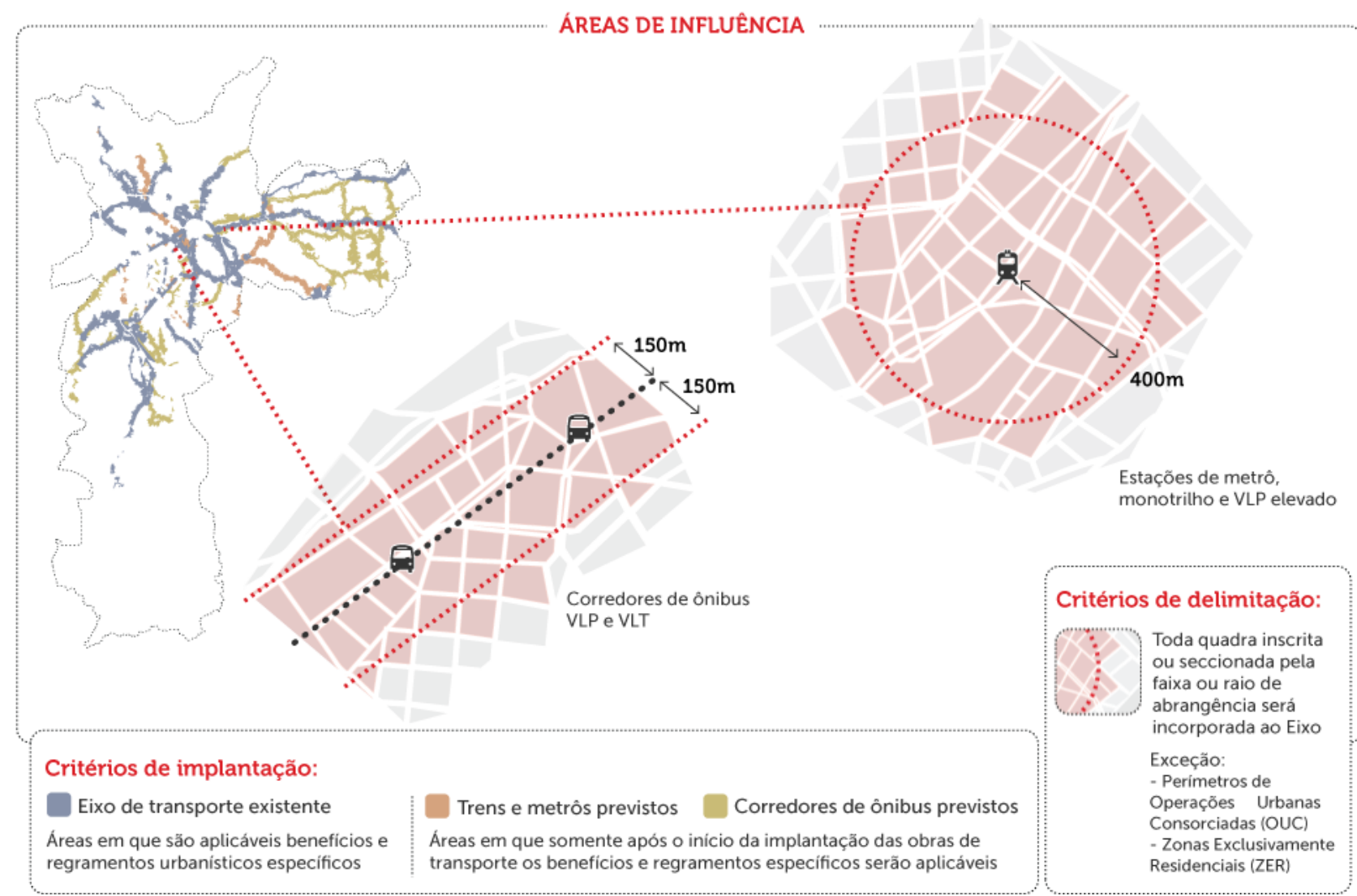

Figura 1 - Eixos de estruturação

Fonte: Plano Diretor Estratégico de São Paulo, 2014 
Os usos privados que fazem parte destas áreas e que dinamizem e articulem a relação entre o térreo dos edifícios e o passeio público serão beneficiados através de usos não computáveis por meio de fachadas ativas e da fruição pública no pavimento térreo. Nestas áreas de abrangência dos eixos de estruturação serão incentivados a construção de uso misto, a implantação de equipamentos e usos institucionais e a ampliação dos espaços públicos.

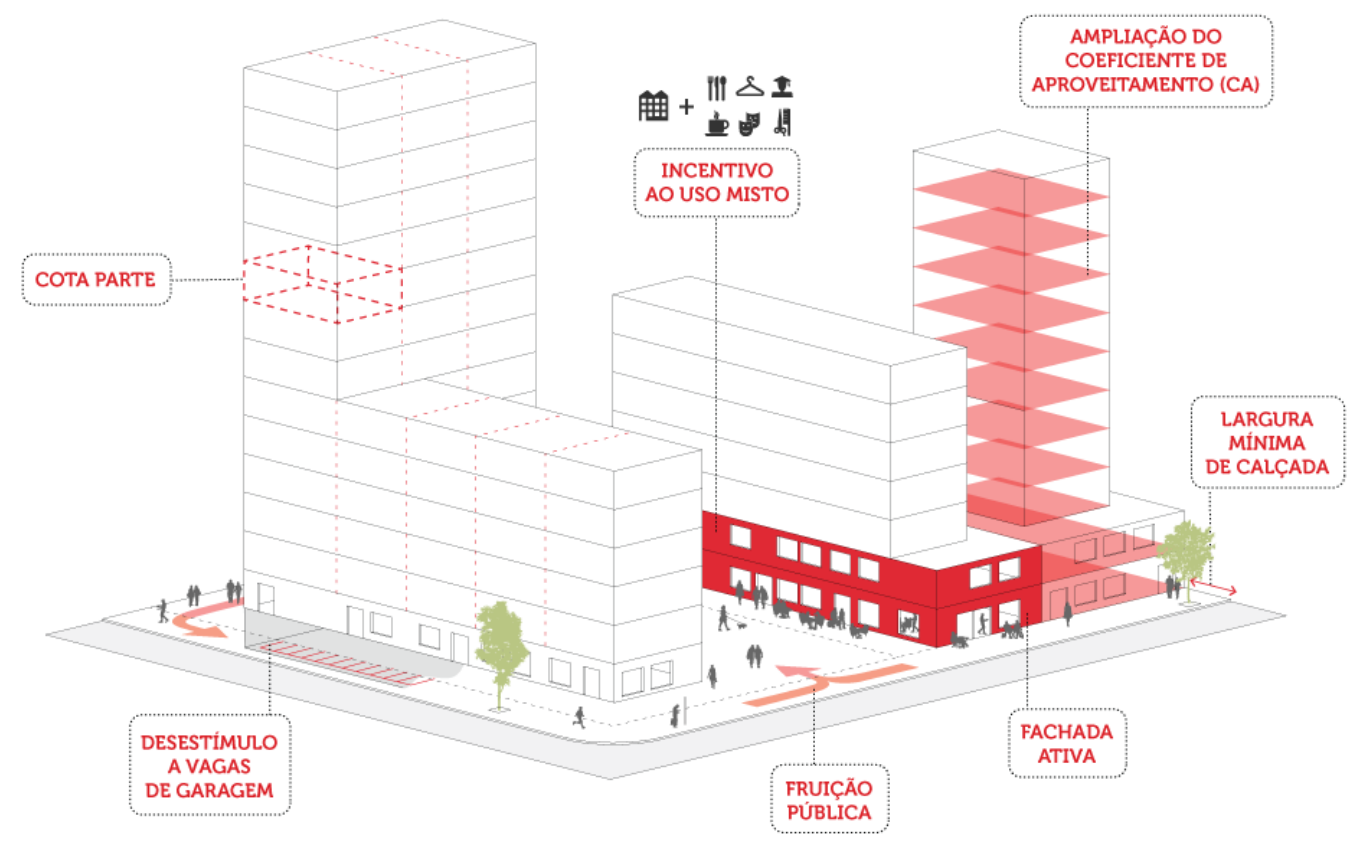

Figura 2 - Situação urbana ilustrativa

Fonte: Plano Diretor Estratégico de São Paulo, 2014

O plano define fachada ativa a que corresponde à ocupação da fachada localizada no alinhamento de passeios públicos por uso não residencial com acesso aberto à população e abertura para o logradouro. Na revisão do Plano Diretor de São Paulo, é um novo padrão urbanístico que visa motivar espaços e calçadas e têm como objetivo promover usos mais dinâmicos desses locais através da interação com atividades instaladas nos térreos das edificações a fim de fortalecer a vida urbana nos espaços públicos. A ideia, com isso, é evitar a multiplicação de planos fechados na interface entre as construções e o passeio público.

O documento determina que em lotes com testada maior que $20 \mathrm{~m}$ com a área do térreo destinada a usos classificados como não residenciais e usos não residenciais toleráveis, não serão computáveis, até o limite de $50 \%$, a área do lote destinada à implementação deste instrumento.
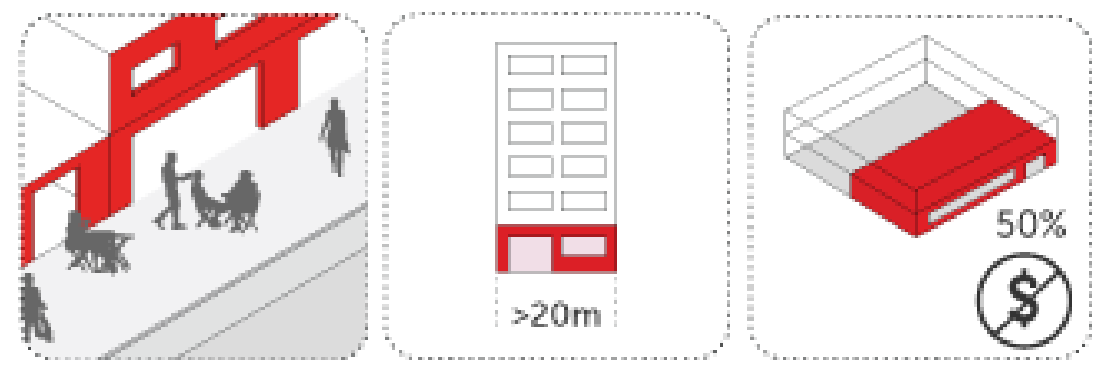

Figura 3 - Estratégia da fachada ativa

Fonte: Plano Diretor Estratégico de São Paulo, 2014

\subsection{Belo Horizonte}

Belo Horizonte também elaborou um projeto de Lei para seu Novo Plano Diretor. Nesta proposta estão reunidas ideias debatidas e aprovadas através da IV Conferência Municipal de Política Urbana, realizada em 2014. Este documento fornece estratégias e diretrizes com destaque para a qualidade de vida, a inclusão, justiça social, equilíbrio econômico e ambiental. 
O objetivo do Novo Plano é orientar o crescimento da cidade de Belo Horizonte. Para isso o plano apresenta regras de controle de adensamento, com 0 intuito de restaurar o equilibro entre 0 desenvolvimento econômico e o interesse da coletividade. Além disso, pretende otimizar o uso dos lotes nas proximidades das áreas centrais e dos corredores de transporte público, ideia apresentada também na revisão do Plano Diretor de São Paulo.

O plano apresenta alguns objetivos e estratégias importantes como, por exemplo, o de democratizar e humanizar o espaço urbano. Esse objetivo vem com a ideia de transformar os espaços públicos em lugares mais saudáveis e democráticos, priorizando as áreas livres de construções, o conforto visual e o trânsito de pedestres, privilegiando a qualidade de vida. Para este objetivo se concretizar foram pensadas em estratégias como

(...) maior aproveitamento do terreno para estimular o adensamento em áreas de centralidades requalificação das centralidades existentes. Incentivo ao uso misto e à fachada ativa, áreas de fruição pública, afastamento frontal integrado à calçada para ampliar áreas coletivas passeios mínimos generosos. (BELO HORIZONTE, Novo Plano Diretor de 2015)

Para o novo Plano Diretor de Belo Horizonte, as fachadas ativas são o térreo de edifícios com serviços, comércio e equipamentos, voltados e abertos para o passeio público. Esse conceito, segundo a gestão municipal, é diretamente associado a melhoria da vida nas calçadas, pois gera diversidade urbana, além de qualificar as áreas onde estão inseridas e garantir o conforto e segurança para os pedestres.

\subsection{Curitiba}

Curitiba é outra das cidades brasileiras que revisou seu Plano Diretor no ano de 2014. O objetivo dos gestores foi definir uma cidade organizada em eixos estruturantes e de adensamento. A ideia é incentivar a ocupação através da verticalização e criar bairros autônomos, atraentes para todos os tipos de usos.

A Lei Municipal 14771/2015 que dispõe sobre a Revisão do Plano Diretor de Curitiba: 2014-2024 orienta o controle do desenvolvimento integrado do município. Dentre as principais seções e capítulos da Lei estão alguns que merecem destaque, como o Artigo 17 do Capítulo I que trata da Estruturação Urbana da cidade. Neste artigo, a política de estruturação urbana se dá através do adensamento e da configuração da paisagem para que se possa buscar o equilíbrio entre o ambiente natural e o construído, através de diretrizes que tem como ação consolidar e ampliar áreas para uso preferencial ou exclusivo de pedestres e também promover a diversificação de usos, mescla de atividades, a fim de equilibrar a oferta de emprego na cidade. Este capítulo demonstra a preocupação em se fazer uma cidade mais voltada ao pedestre.

A seção II que trata do Parcelamento, Uso e Ocupação do solo têm por objetivo atender a funções econômicas e sociais da cidade, compatibilizando desde o sistema viário, transporte e demais serviços urbanos até as condições ambientais e o saneamento básico. Para isso a revisão propõe o Artigo 29 que apresenta a diretriz das fachadas ativas, onde diz que

Art. 29. A fachada ativa é o uso não-residencial com acesso direto e abertura independente para o logradouro, no nível da circulação de pedestres, de modo a estimular o uso misto nas edificações e reduzindo o deslocamento do uso de serviços. (CURITIBA, Lei Municipal 14771 de 2015)

Segundo o parágrafo primeiro deste artigo, o poder público estabelecerá alguns critérios para a aplicação da fachada ativa, através de estudos que definam áreas prioritárias de intervenção, variedades de usos, funções e diversificação arquitetônica das fachadas e qualificação dos espaços de uso público.

O parágrafo segundo estabelece que se o empreendimento apresentar $50 \%$ da área do pavimento no nível da calçada destinada a uso não residencial será concedido um pavimento como benefício sem que sua área seja computável. Porém a fachada ativa só é aplicável, conforme a Lei de Zoneamento, Uso e ocupação do Solo, para imóveis de categoria comercial e de serviços, de pequeno e médio porte. Além disso, o benefício de acréscimo de pavimentos e de potencial construtivo em edifício com fachada ativa não são cumulativos com outros parâmetros e incentivos. 


\section{A IMPORTÂNCIA DA FACHADA ATIVA PARA RETOMAR A RELAÇÃO ENTRE O EDIFÍCIO E A RUA}

As fachadas ativas ou os plinths, mesmo com diferentes usos e tratados de variadas formas nos planos diretores, têm a mesma função e detém a mesma importância, enriquecer a cidade. Solá-Morales (2001) destaca que "a boa cidade é aquela em que bons edifícios particulares têm valores sociais que os extrapolam". No seu ponto de vista, esses elementos que se caracterizam por serem ou estarem em um domínio privado, passam a ser demasiadamente significativos quando absorvem usos públicos.

A importância do espaço público não está, certamente, em ser mais ou menos extenso, quantitativamente dominante ou protagonista simbólico, senão referir-se entre si os espaços privados fazendo também deles patrimônio coletivo. Dar caráter urbano, público, aos edifícios e lugares que sem isso seriam somente privados, esta é a função dos espaços públicos - urbanizar o privado, quer dizer convertê-lo em parte do público. (SOLÁ-MORALES, 2001)

É imprescindível para uma boa cidade, a presença de elementos de transição de qualidade. Se eles não são projetados, se as fachadas não são ativas e os edifícios se fecham para a rua, surgem "zonas mortas" (MINTZ, 2015) ou "lugar morto" (JACOBS, 2000). E esses espaços mortos fazem com que as pessoas se desinteressem por caminhar perto deles, diminuindo a intensidade de trânsito naquele local.

Unwin (2013) ressalta que esses elementos que criam um local de passagem e transição entre um espaço a outro podem ter desde benefícios práticos, como o controle de uma edificação, como também efeitos psicológicos, como o contraste entre o movimento externo da rua e o interior tranquilizante.

No artigo A cidade ao nível dos olhos: estratégia do plinth, Karssenverge e Laven (2015), assim como os diversos autores que fazem parte da coletânea de artigos do livro A cidade ao nível dos olhos - lições para os plinths, tratam destas fachadas ativas como parte crucial e de fundamental importância para se criar uma boa cidade ao nível dos olhos. Para eles, as pessoas experimentam a cidade não somente através do "espaço público", mas sim da "esfera pública", que inclui as fachadas dos prédios e tudo o que pode ser visto ao nível dos olhos.

É por isso que os plinths são um elemento qualificador importante para a experiência e atratividade do meio urbano. Se o andar térreo é vibrante, as pessoas podem ter uma experiência positiva ao passar por ele, porém se ele for um muro cego, a experiência de passar por este local será pouco positiva. Através de pesquisas, eles concluíram que se o local é "seguro, limpo, relaxado e fácil de compreender, [...] esses visitantes permanecerão três vezes mais tempo e gastarão mais dinheiro do que numa estrutura antipática e confusa". (KARSSENVERGE; LAVEN, 2015)

Ainda conforme Karssenverge e Laven (2015), "o andar térreo pode ocupar somente $10 \%$ de um prédio, mas ele determina $90 \%$ da contribuição do prédio à experiência do entorno", é por isso que o andar térreo impacta claramente a vida pública. De acordo com os estudos realizados por Gehl et al. (2015) "o número de paradas e outras atividades é sete vezes maior em frente de fachadas ativas, em comparação a fachadas passivas". Além disso, as atividades realizadas por essas pessoas nesses locais não se tratavam apenas de consumo, pois diante destas fachadas ativas as pessoas paravam para amarrar sapatos, falar no celular, organizar sacolas e conversar com os outros cidadãos muito mais do que em fachadas fechadas e rígidas.

Gehl (2013) dá enorme importância ao andar térreo, pois é a área onde os pedestres experimentam mais intensamente a cidade, onde eles podem ter contato com os detalhes, materiais e outras pessoas que estão dentro ou perto destes espaços. "Caminhar na cidade permite longo tempo para vivenciar aquilo que as áreas ao nível da rua têm a oferecer [...] As caminhadas tornam-se mais interessantes e significativas, o tempo passa rapidamente e as distancias parecem mais curtas." (GEHL, 2013) Porém quando os térreos não são interessantes, as fachadas são fechadas ou monótonas, as caminhadas parecem longas, pobres de experiência e sem sentido, e isso faz com que as pessoas desistam de caminhar.

Tendo em vista esta consideração, Karssenberg et al (2015) acrescenta que a qualidade desses elementos - as fachadas ativas - é extremamente importante tanto para promover a equidade e inclusão social como para aprimorar a sustentabilidade ambiental. Ele acredita que regulamentos e instrumentos com o intuito de fortalecer a relação do andar térreo com a rua podem melhorar a interação entre os espaços privados, semiprivados, semipúblicos e públicos. 


\section{CONCLUSÃO}

Diante da demonstração da importância das fachadas ativas para a qualidade de vida nas cidades, percebe-se que a arquitetura tem papel fundamental na definição de espaços urbanos melhores. Conforme demonstra Bruno Zevi (1996), há dois graves equívocos que podem tornar ridícula a interpretação sobre a arquitetura. Um deles é de que a experiência arquitetônica só é possível no interior do edifício, ou seja, que não considera o espaço urbanístico ou não o dá valor. A segunda é que o instrumento crítico para julgar uma obra de arquitetura se finda através da interpretação espacial do edifício. Portanto, vê-se que pensar arquitetura vai muito além dos limites do edifício, isso abrange todos os elementos conectores e seu entorno.

Sob o ponto de vista de Argan (2005), a arquitetura forma um todo com a cidade, de modo que "tudo que não funciona na cidade, reflete em última análise, os defeitos da cultura arquitetônica ou revela sua incapacidade de preencher suas funções institucionais." (ARGAN, 2005) Sendo assim, segundo ele, é preciso reconhecer que a arquitetura é a primeira das técnicas urbanas, não podendo ser considerada apenas como uma das belas artes, e que ela é responsável pela gestão das cidades e suas mudanças. Logo, para ele, a grande tarefa dos arquitetos atualmente é recuperar a cidade.

Para Gehl (2013), nos últimos anos, planejar as cidades tem sido uma tarefa difícil. "Não se reconhece que a vida na cidade tenha se distanciado de seguir a tradição para tornar-se uma função urbana vital, exigindo consideração e cuidadoso planejamento de profissionais." (GEHL, 2013) Ele acredita que agora, a partir de estudos e informações sobre o que deve ser feito, existe um razoável entendimento entre a forma física da cidade e o comportamento humano, principalmente porque os habitantes das cidades tornaram-se muito mais ativos "na reivindicação por um urbanismo voltado às pessoas." (GEHL, 2013) Em virtude disto, atualmente estão surgindo, após anos de negligência, grandes projetos e estratégias inspiradoras.

Diante desta realidade, conclui-se que a arquitetura pode ser uma aliada do urbanismo. Mesmo que um edifício se desenvolva dentro de um lote privado, existe a oportunidade, a partir de um projeto, de desenvolver o interesse público através desta arquitetura, abrindo possibilidades de uso para todos. Portanto, ao projetar edifícios, se constrói a cidade, e isso tem um impacto que extrapola os limites do lote.

Só quando o arquiteto dá atenção suficiente não somente ao espaço ocupado pelos edifícios que projeta, mas também ao espaço não ocupado por seus edifícios... só quando ele projeta o entorno de seus edifícios como espaços positivos ou somente quando concebe tanto o lote do edifício como um único pedaço de arquitetura e as áreas descobertas como espaço exterior, ele realmente começa a projetar espaço exterior. (ASHIHARA, 1982)

A partir disso, surge a premissa de que muito mais do que a arquitetura em si, é preciso pensar no entorno dela, para que sua função não se limite através das paredes. Eduardo Yázigi (2000) destaca em seu livro, a importância do entorno, afirmando que todos devem ter "o direito ao entorno." (YÁZIGI, 2000) Ele vê a possibilidade de viabilizar este direito, não somente através dos arquitetos, mas da vontade deles aliada a uma política urbana estamentada. Para que isso aconteça é preciso uma redefinição de um partido que trate sobre o futuro dos espaços públicos. Isso incluiria estratégias de zoneamento, uso e ocupação, códigos de obras, entre outros.

O zoneamento de uso e ocupação, mexendo com as atividades do privado e do particular, assim como suas taxas de incidência nos lotes, acaba definindo as qualidades intrínsecas, físicas e humanas do espaço público. Mas é uma regulação totalmente dependente das relações de forma dos agentes sociais que interagem na cidade. A presença ou não de um shopping ou loja de departamentos de grande superfície pode alterar toda vida e comercio de rua de suas vizinhanças. (YÁZIGI, 2000)

Conforme Karssenberge e Laven (2015) a maioria dos arquitetos ainda são focados em desenhar prédios ao invés de criar boas ruas, porém os autores ressaltam que se as pessoas quiserem boas ruas, nas próximas décadas terão que colaborar entre si e com as autoridades locais para que isso aconteça. Mesmo que $o$ arquiteto entenda a importância de seu projeto para qualificar o entorno do edifício, o resultado nem sempre é o produto de sua intenção individual nem tão pouco restrito a ele. Além do profissional existem as exigências do proprietário, é por isso que a administração pública tem um papel fundamental, para, a partir de leis regulamentadoras e códigos de edificações, influir no modo como os lotes são ocupados. 
Em relação a este assunto, Ton Schaap (2015) sugere que os arquitetos comecem a desenhar considerando o ponto de vista da rua, e não do edifício, só assim se gerarão boas ruas e calçadas e a arquitetura passará a contribuir de forma positiva para a cidade. Além dos arquitetos, detentores de grandes ideias que podem melhorar os centros urbanos a partir dos projetos de arquitetura, o governo local e os incorporadores têm um papel importante para que a cidade se torne um local melhor através da contribuição dos edifícios.

Sendo assim, a pesquisa se torna relevante no sentido de salientar aos arquitetos e estudantes de arquitetura que um projeto não deve ser pensado somente nos limites físicos do edifício, no seu programa de necessidades e objetivos principais. Ele deve ser contextualizado e relacionado com a cidade, de modo a aliar as funções principais privadas ou restritas do projeto/obra à promoção de boas calçadas para se transitar e se relacionar. Além disso, através do incentivo municipal para a ocupação destes usos no nível da calçada, e consequentemente da melhora da permeabilidade no térreo, podendo ser facilmente acessado por toda a população, o edifício passa a ser um instrumento que contribui para a conexão com o espaço público, qualificando-o.

É valido destacar que, partindo desta ideia, cada um pode e deve melhorar a cidade em que vive, de maneira que existam artifícios e incentivos para esta intenção. Não se deve deixar na responsabilidade apenas do poder público de criar estes espaços coletivos, porém é de grande valia que as autoridades e planejadores, a partir de normas e planos diretores, impulsionem o projeto de edificações mais interligadas ao tecido urbano. Mesmo que a discussão sobre as fachadas ativas ainda é inicial, esta diretriz pode antever mudanças com relação à transição entre a arquitetura e a cidade, assunto demasiadamente importante para a melhora da qualidade de vida dos centros urbanos.

\section{BIBLIOGRAFIA}

ARGAN, G. C. História da arte como história da cidade. Tradução Pier Luigi Cabra. 5ª Ed. São Paulo: Martins Fontes, 2005.

ASHIHARA, Y. El diseño de espacios exteriores. Barcelona: Gustavo Gili, 1982.

BALSINI, A. R. Espaços de transição: entre a arquitetura e a cidade. 2014. 297f. Dissertação (Mestrado em Arquitetura e Urbanismo) - Universidade Presbiteriana Mackenzie, São Paulo, 2014.

BELO HORIZONTE. Novo Plano Diretor de 2015. Belo Horizonte, MG. Disponível em <http://www.cmbh.mg.gov.br/sites/default/files/docs/20150924_cartilha_plano_diretor_final.pdf> Acesso em: 25 de jan de 2016.

CASTEX, J. PANERAI, P. Notas sobre a estrutura do espaço urbano. Tradução: Décio Rigatti. Extraído da Revista L'Architecture d'aujourd'hui n 153, dezembro de 1970.

CURITIBA. Lei Municipal $n^{\circ} 14771$ de 2015. Revisão do Plano Diretor de Curitiba. Curitiba, PR. Disponível em <http://www.curitiba.pr.gov.br/conteudo/projeto-de-lei/1629> Acesso em: 25 de jan de 2016.

GEHL, J. et al. Encontros imediatos com prédios. In KARSSENBERG, H. et al. A cidade ao nível dos olhos: lições para os plinths. Porto Alegre: EDIPUCRS, p. 29-35, 2015.

GEHL, J. Cidades para pessoas. 2ª Ed. São Paulo: Perspectiva, 2013.

HERTZBERGER, H. Lições de Arquitetura. São Paulo: Martins Fontes, 1999.

JACOBS, J. Morte e vida das grandes cidades. São Paulo: Martins Fontes, 2000.

LYNCH, K. A imagem da cidade. São Paulo: Martins Fontes, 1980.

KARSSENBERG, H. et al. A cidade ao nível dos olhos: lições para os plinths. Porto Alegre: EDIPUCRS, 2015.

KARSSENBERGE, H.; LAVEN, J. A cidade o nível dos olhos: estratégia do plinth. In KARSSENBERG, Hans et al. A cidade ao nível dos olhos: lições para os plinths. Porto Alegre: EDIPUCRS, p. 14-25, 2015.

MINTZ, N. Pela força de 10. In KARSSENBERG, Hans et al. A cidade ao nível dos olhos: lições para os plinths. Porto Alegre: EDIPUCRS, p. 81-85, 2015.

PANERAI, P. Análise Urbana. Tradução Francisco Leitão. Revisão Técnica de Sylvia Ficher. Editora Universidade de Brasília. Brasília, 2006.

SÃO PAULO. Lei n 16.050 de 2014. Plano Diretor Estratégico do Município de São Paulo. São Paulo, SP. Disponível em <http://gestaourbana.prefeitura.sp.gov.br/entenda-o-projeto-de-lei-68813/> Acesso em: 25 de jan de 2016.

SCHAAP, T. Desenhar a partir da rua. In KARSSENBERG, H. et al. A cidade ao nível dos olhos: lições para os plinths. Porto Alegre: EDIPUCRS, p. 101-105, 2015.

SITTE, C. A construção das cidades segundo seus princípios artísticos. São Paulo: Editora Ática, 1992. 
SOLÁ-MORALES, M. de. Espaços públicos e espaços coletivos. In: Os centros das metrópoles: Reflexões e propostas para a cidade democrática do século XXI. São Paulo: Ed. Terceiro Nome, Viva o Centro, Imprensa Oficial do Estado, p. 101-108, 2001.

UNWIN, S. A análise da arquitetura. 3를. Porto Alegre: Bookman, 2001.

YÁZIGI, E. O mundo das calçadas: por uma política de espaços públicos. São Paulo: Humanitas, 2000.

ZEVI, B. Saber ver arquitetura. 5ª ed. São Paulo: Martins Fontes, 1996. 